\title{
The Impacts of Leadership Styles and Organisational Cultures on Public Innovations in the Emirates
}

\author{
Ahmed Mohamed Alkindi ${ }^{1} \&$ John Chandler ${ }^{2}$ \\ ${ }^{1}$ Docklands Campus, University Way, London, United Kingdom \\ ${ }^{2}$ Stratford Campus, Water Lane, London, United Kingdom \\ Correspondence: Ahmed Mohamed Alkindi, Docklands Campus, University Way, London, United Kingdom. \\ E-mail: aaalkindi@gmail.com
}

Received: April 15, 2018

doi:10.5539/ijbm.v13n7p1
Accepted: May 9, 2018

Online Published: June 15, 2018

URL: https://doi.org/10.5539/ijbm.v13n7p1

\begin{abstract}
The role of national and organisational culture in innovation and the implications for strategy remains a source of professional and academic interest. The purpose of this paper is to investigate how national culture and organisational culture influence the relationship between leadership style and innovation strategy. A quantitative approach is adopted for the research methodology utilising structural equation modelling (SEM) to test the hypotheses and explore the relationships between the observed variables. The findings reveal that leadership styles have distinct relationships with innovation strategies and point to a duality in terms of transformational and transactional leadership and innovation. The relationship between national culture dimensions provides support for the notion of a balanced approach to innovation management. National culture does not appear to be an entirely restraining factor in innovation. The findings indicate that cultural dimensions at national and organisational level overall exert a small moderating effect suggesting that the relationship between leadership style and innovation strategies is not wholly bound by national and organisational culture.
\end{abstract}

Keywords: Innovation, leadership style, transformational leadership, transactional leadership, national culture, organisational culture, UAE, public sector

\section{Introduction}

he role of national and organisational culture on innovation and the implications for strategy remains a source of professional and academic interest. Understanding factors that influence innovation in organisations has been the subject of numerous studies that have explored leadership style. In an era of globalisation and dynamic and complex business environments there is an increasing imperative to understand the relationship between these dimensions. Research into culture and innovation indicate the influence of culture at both a national and organisational level (Nazarian et al., 2014; House et al., 2004; Pizam, 1993). Evidence indicates that national culture holds greater influence on organisational culture and can exert significant influence on robust organisational strategies and organisational design (Spolaore \& Wacziarg, 2012). In contrast, organisations with deliberate strategies can override biases from national culture to address dilemmas and challenges arising from context or events (Smale, 2016; Helmreich \& Merrit, 1998). Within culture leadership is recognised as of paramount influence on innovation as leaders' style can dictate the degree to which innovative behaviour is fostered among subordinates.

Managers in the police sector in UAE are operating within highly diverse and inter-cultural contexts that creates greater emphasis on understanding the impact on innovation strategies. Strategic innovation approaches can be a function of national culture influencing the decision-making and actions of individuals and groups in accordance with complex interconnected and mutual norms and values (Smale, 2016). Rather than operate in isolation, elements of both national and organisational culture represent a complex web interplaying in constant flux influenced by contextual factors and emergent tensions and challenges (Trompenaars \& HampdenTurner, 1998). Therefore it is important to understand the impacts of dimensions of culture on innovation strategies to identify conflict and enhance alignment in terms of organisational design.

The rapid pace and pervasiveness of change in the UAE police sector has focused predominantly on the content and processes of change at the implementation level. A key factor has been strategic dependency on a top-down programme of change management based on an external consultancy model (Biygautane \& Al-Yahya, 2011). 
However, the shifting context may have implications for innovation strategy. Wide institutional change is acknowledged to hinge on the role of middle managers to implement change plans (Baptista et al., 2017). However little is known about how change is being implemented at this level. Accordingly this study investigates the impact of national culture and organisational culture and leadership style on innovation strategies. Specifically, research has shown that transformational leadership is a major determinant of a firm's innovativeness (Engelen et al., 2014; Jung et al., 2003). However, limited research has underlined the role of leadership styles in different cultures to increase organisational innovativeness. The dynamic between these factors represents a critical focus for this research and a research gap in the public sector (Moynihan, et al., 2012; Wright et al., 2012). While both transformational leadership (Paulsen et al., 2013; Gumusluoğlu \& Ilsev, 2009; Vera \& Crossan, 2004; Howell \& Higgins, 1990) and transactional leadership styles (Jansen et al., 2009; Bono \& Anderson, 2005; Goodwin et al., 2001; Avolio et al., 1999) have evidenced impacts on innovation, there is a lack of consensus on their effects.

\subsection{UAE Public Sector}

As part of the public sector in the UAE, the police face a rapid and continuous change innovation programme driven by compliance with the national Excellence Vision for 2021 which demands public sector readiness to uniformly implement service-enhancing changes (Al-Darmaki, 2015). The programme focuses on three main areas of innovation, vision achievement and empowerment, to ensure the achievement of high public satisfaction levels (Al Maktoum, 2015). The National Innovation Strategy (NIS) is a further major driver of public sector change grounded in a commitment to an innovation culture (UAE Gov, 2015). The country's aim is to transform itself by 2021 into a global leader in innovation. A major development is the emphasis on incorporating new communication channels within extant organisational and strategy processes and practices (Bruhn and Ahlers, 2017).

\section{Literature Review}

\subsection{Leadership Styles}

While there is extensive research on leadership (Moynihan et al., 2012; Wright, et al., 2012) and creativity in the public sector (e.g., Berman \& Kim, 2010), there is limited empirical research on the relationship between leadership, culture and innovation strategy. How innovation leaders encourage and establish an innovative and creative organisational culture is the foundation for leadership best practice (Mumford \& Hemlin, 2017). Leader generation of mutual trust, challenging the status quo, motivation of subordinates and importance placed on results is considered to be the basis for fostering innovation and creativity (Harper \& Becker, 2004). In the bureaucratic public sector context research suggests that certain leadership styles may be more suited to addressing the implementation of innovations (Parry \& Proctor-Thompson, 2002; Shamir \& Howell, 1999). To overcome organisational inertia transformational leadership theory underlines the role of organisational leaders as change agents who initiate and implement new directions within organisations (Caillier, 2015). In order to institutionalise change, transformational leaders need to deconstruct old practices and establish novel ones based on innovative visions and ideas (Waldman \& Bass, 1991).

Kim and Yoon (2015, p. 151) define transformational leadership as valuing "organisational change through the recognition of the need for change, the creation of a clear vision, intellectual stimulation and individual consideration, and the implementation of changes". Transformational leaders strive for new ways of doing things, develop new opportunities when faced with challenges, do not support the status quo, transform their environment instead of reacting to it, and inspire followers to perform better than originally expected (Dvir et al., 2002; Lowe et al., 1996). Attributes of transformational leadership are thus highly applicable to innovation and exploration (Jansen et al., 2009). Transformational behaviours facilitate innovation by enabling learning feedback flows as a result of effective communication and generating commitment towards realisation of innovation (Vera \& Crossan, 2004). Idealised influence and inspirational motivation further enable the construction of ideological perspectives which help to link individual identities with that of the organisation (Jansen et al., 2009; Jung et al., 2003; Shamir et al., 1993) and enlarge employees' intrinsic motivation to participate in exploratory innovation (Jansen et al., 2009).

In contrast transactional leaders are concerned with the application of rules, regulations and organisational policies. Transactional leadership involves the degree to which a leader establishes a clear reward system with followers and takes action to uphold this exchange system on the basis of follower behaviour (Bass \& Riggio, 2006). Transactional leadership involves contingent reward, or providing rewards to followers for performance, active management by exception, which implies attending to followers' mistakes, and passive management by exception, which involves ignoring followers' mistakes until the problem becomes severe enough to require 
intervention (Avolio \& Bass, 2002). Thus, transactional leadership is more of an economic exchange between leaders and followers in contrast to the emotional exchange involved in transformational leadership (Lord et al., 1986).

The greater the tendency for a manager to be transactional, the more the innovation process is expected to be implemented in a top-down manner. Transactional leaders may take orders and send orders without the sufficient ability to listen to their subordinates. Transactional leadership behaviours are suggested to promote exploitative innovation through learning flows which are fed forward by means of the provision of individual and group rewards for the generation of new ideas to exploit current services, products or markets and gain scale and scope advantages (Jansen et al., 2009). The active management by exception and contingent reward behaviours characteristic of transactional leadership may provide the focus and control required to drive efficiency and to make consistent improvements in the conduct of active routines and practices.

\subsection{Culture}

The style of leadership and its relationship with innovation strategies can both be impacted by national and organisational culture. National culture is the beliefs, values and assumptions embedded since early childhood that differentiate different groups of people from each other (Beck \& Moore, 1985) and is deeply entrenched in daily life and relatively resistant to change (Newman \& Nollen, 1996).

Hofstede's cultural dimensions framework (Hofstede, 1980, 2001) and the GLOBE framework (House et al., 2004) remain by far the most widely applied frameworks used in studies of cross-cultural differences (Bockstedt et al., 2015). National culture dimensions of power distance, collectivism, masculinity and uncertainty avoidance are widely cited in terms of their impact on behaviour of individuals, groups and organisations (Bockstedt et al., 2015). Power distance (PDI) measures the distribution of power within a society in terms of the degree to which its members expect and accept inequality. High PDI scores translate into hierarchical and rigid national or organisational structures (Hofstede, 2001) in which decision-making information and information sharing is potentially restricted by hierarchical features (van Everdingen \& Waarts, 2003). In low-PDI countries new organisations tend to be smaller and more organic, with high information-processing capabilities and informal communication between superiors and subordinates (Shane, 1992). Evidence highlighting a negative correlation between power distance and innovation (Rinne et al., 2012; Shane, 1992, 1993) points to the conclusion that countries with high power distance cultures may face challenges in innovating.

The dimension of uncertainty avoidance expresses the degree to which the members of a society feel uncomfortable with uncertain and ambiguous situations. Countries exhibiting strong uncertainty avoidance maintain rigid codes of belief and behaviour and are intolerant of unorthodox behaviour and ideas (Hofstede, 1980). While low-UAI societies tend to be more open to change and new ideas, members of high-UAI societies tend to perceive novelty as dangerous and hence to resist it. Organisations located within high-UAI cultures tend towards significant degrees of inflexibility and resistance to change (Efrat, 2014). Such cultures are reflected in strict managerial control in terms of rules and regulations and direction over the roles and responsibilities of organisational members (Ayoun \& Moreo, 2008).

The value placed on personal freedom in individualistic cultures (Waarts \& Van Everdingen, 2005; Herbig \& Dunphy, 1998) is held to provide employees with increased opportunities to attempt new innovations (Kaasa \& Vadi, 2010; Williams \& McGuire, 2005; Shane, 1993). In contrast a collectivist national culture emphasises interdependence and building friendly relationships, potentially at the expense of task achievement (Kim et al., 1994). Collectivist societies tend to impede communication upwards through the social hierarchy, over-centralise authority, rely on rules and procedures over trust, and resist the radical social changes that often accompany innovation (Bockstedt et al., 2015).

The fourth cultural aspect, masculinity, has largely been neglected in the literature (Efrat, 2014). More feminine-oriented cultures are argued to place greater importance on people and are characterised by a more supportive environment. In more masculine societies, the emphasis is on ego, financial rewards, performance, and achievements (Hofstede, 2001). According to previous studies, high-MAS societies display a greater tendency towards invention and innovation based on achievement triggers (Shane, 1993) and masculinity can impact national innovation levels (Efrat, 2014).

Organisational culture is recognised as one of the key factors affecting innovation (Carmeli, 2005). The term organisational culture identifies the beliefs, standards, and assumptions common to members of an organisation (Miron et al., 2004; Cameron \& Quinn, 1999). Different types of organisational cultures potentially promote or hinder innovation (Naranja-Valencia, 2015) and can impact the stimulation of innovation and creativity of groups and individuals within the organisation (Martins \& Terblanche, 2003). 
The Competing Values Framework (CVF) (Cameron and Quinn, 2011) describes and operationalise types of organisational cultures and is one of the most broadly adopted models in empirical research on organisational culture (Naranjo-Valencia et al., 2015; Katzenbach et al, 2012). This framework assesses the dominant organisational culture based on four types: Clan culture, Hierarchy culture, Adhocracy culture, and Market culture. Each dimension is associated with a number of key attributes. A Clan orientated culture reflects a friendly working environment, where people emphasise the same shared values and common goals. This type of organisational culture is the least competitive of all four. The predominant atmosphere is based on trust, respect and honesty with an emphasis on empowerment and employee evolvement. Adhocracy orientated cultures are dynamic and creative environments with a focus on innovation and risk taking. Market cultures distinguish results-based organisations that emphasise competition, producing results and getting things done. In this culture type, people focus on reaching goals and outcome excellence. The Hierarchy culture is a formalised and structured work environment based on coordination and control of process efficiency and estimated outcomes (Cameron \& Quinn, 2011).

One objective of this paper is to explore the moderating effects of culture at national and organisational level. Research has shown that power distance can act as a moderator in various organisational relationships and on diverse organisational outcomes. While research is limited on whether power distance acts as a moderating factor between leadership and innovation, some evidence suggests a moderating effect. Thomas (2015) found that power distance can moderate the relationship between empowering leadership and followers' psychological empowerment and self-leadership, with accentuated effects in higher power distance cultures. Additionally Imcharoen (2011) focusing on high and low power distance teams provided evidence of power distance as a moderator on radical innovation. Meanwhile collectivism may function as a moderating variable influencing the relationship between leadership styles and innovation strategies (Walumbwa \& Lawler, 2003; Jung \& Avolio, 1999). In terms of uncertainty avoidance Moosmayer and Koehn (2011) found that uncertainty avoidant managerial values moderated organisations' ability to transform different types of innovations into organisational performance. More broadly, uncertainty avoidance negatively moderated the relationship between innovation and growth (Rauch et al., 2011).

Investigations of the factors promoting creative employee performance have highlighted organisational culture as either a positive or negative moderator in the relation between leadership and creative performance (Golden \& Shriner, 2017; Hartnell et al., 2011; Prajogo \& McDermott, 2011). Hamzah et al., (2013) investigated the moderating role of organisational culture focusing on the relationship between leadership competency and employee job performance, showing that each organisational culture dimension of hierarchical, developmental, rational and group (Quinn \& Spreitzer, 1991) had a moderating influence. Adhocracy orientated cultures have been found to significantly moderate the relationship between transformational leadership and employee creative performance (Golden \& Shriner, 2017). Findings further revealed that only under higher degrees of adhocracy cultures was transformational leadership effective at raising levels of creative performance (Golden \& Shriner, 2017). Organisational culture further has a strong moderating effect on the relationship between leadership behaviour and organisational commitment. In particular bureaucratic, innovative and supportive cultures significantly influenced the relationship between participative and supportive leadership behaviours and organisational commitment (Yiing \& Ahmad; 2009; Li, 2004). Furthermore the relationship between directive leadership behaviour and organisational commitment was enhanced by the moderating influence of innovative and supportive cultures. A bureaucratic culture however did not significantly moderate the relationship.

\subsection{Innovation Strategies}

Governments operate in challenging fiscal situations and rapidly changing environments, continually driving the exploration of innovative strategies that change internal processes and structures, service delivery, transparency requirements and communications with their users (Reddick and Turner, 2012; Bertot et al., 2010). Organisations may adopt one of three generic approaches: top-down innovation, bottom-up or inside-out innovation strategies. A top down change process has been noted as primarily management-driven and the pursuit of consensus is not necessarily a priority. The literature suggests that a 'top down' governance structure could be a common innovation method for agencies, particularly in risk-averse environments or where there is staff resistance to change. In certain cultures this is argued to potentially cause disaffection among employees if not also associated with a bottom-up process involving individual empowerment and personal investment in the process (Skordoulis, 2012). A bottom-up approach emphasises the critical role of employee knowledge and skills in generating innovation and organisational performance (Andries and Czarnitzki, 2014). Bottom-up innovation efforts benefit from high levels of employee engagement, while top-down innovation efforts benefit from direct alignment with the company's goals. 
Inside out innovation strategies are defined as innovation processes that predominantly depend on the core skills, knowledge and capabilities embedded within the organisation to drive change and inmovation (Goyal et al., 2015). This adopts a resource-based view focused on inside-out innovation processes in the public-sector which begins with identification and awareness of core internal capabilities at an individual, team and organisational level (Cortimiglia et al., 2016). This type of innovation can result in higher efficiency and increased speed in adapting to changing conditions by exploiting unused innovations and making them accessible to external users involving the transfer or channelling of ideas and innovation to the external environment (Osterwalder and Pigneur, 2010; Gassman and Enkel, 2004). In the UAE the government has cited a vision to become one of the leading forces in the world and is committed to developing and exploiting its innovations regionally and globally. An in-out approach to innovation is consistent with public sector orientation and environmental conditions to drive efficiency gains internally and motivating key actors in the public sector to look within their departments for alternate innovation resources that can be harnessed and utilised (Pablo et al., 2007).

\subsection{Conceptual Framework/Hypotheses}

The theoretical foundation of this study is situated in the overlapping themes of leadership, culture and innovation. The literature has emphasised the potential differences in innovation strategies in the form of bottom-up, top-down and inside-out implied by different leadership styles that can be influenced by different cultures. Consequently, this focus addresses the research gap and explores several lines of inquiry to examine the relationship between two key leadership styles, national culture and organisational culture and innovation strategy as illustrated in Figure 1.

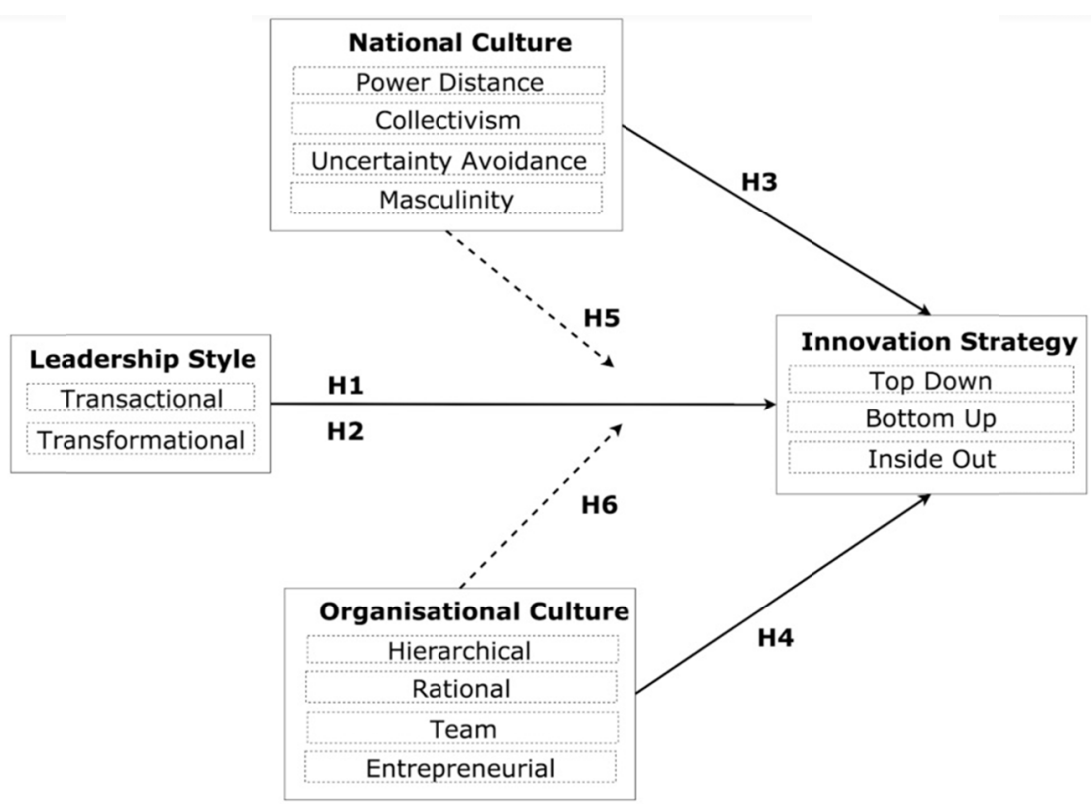

Figure 1. Theoretical framework

In relation to this the following key hypotheses are formulated:

H1 Transformational leadership style is positively related to innovation strategy.

H2 Transactional leadership style is positively related to innovation strategy.

H3 National culture dimensions are positively related to innovation strategy.

H4 Organisational culture orientation is positively related to innovation strategy.

H5 National culture moderates the relationship between leadership style and innovation strategy.

H6 Organisational culture orientation moderates the relationship between leadership style and innovation strategy.

\section{Methods and Procedure}

A quantitative approach is adopted for the research methodology utilising structural equation modelling (SEM) 
to test the hypotheses and explore the relationships between the observed variables. A survey was conducted based on a sampling frame of 16,000 police personnel in the UAE across the seven Emirates in the main government departments. A probability-based sampling strategy was adopted, and more specifically a stratified probability sampling technique. The aim was to target a sub-group of personnel by the level of their position. As the focus was on middle managers, a random sample of lower level police personnel was taken; junior level management and non-management personnel (i.e. rank of Captain and lower) consisting of $70 \%$ of the sample frame. Not counting the demographic items, the questionnaire comprised 54 items across 5 sections: national culture, organisational culture, leadership style, innovation strategies and innovation performance. Measurement was based on established scales from previous research with strong validity. National culture was based on the cultural values (CVSCALE) adopting 14 items from a 26-item scale to evaluate cultural orientations (Yoo et al., 2011) based on Hofstede's four cultural dimensions (1980 and 2001). Organisational culture was measured using a shortened 13 item scale of organisational culture for the public sector adapted from Cameron and Quinn's (2006) Competing Values Framework focused on four key types of organisational culture namely Hierarchy, Clan (Team), Adhocracy (Entrepreneurial) and Market (Rational) culture. Innovation strategies scale was adopted from Deschamps (2005) with two question items for in-out innovation, and four items measuring top down innovation and five items assessing bottom up innovation. A further four question items on innovation performance are included adapted from the literature (García-Morales et al., 2008; Antoncic \& Hisrich, 2001). For transformational leadership a seven-item scale by Nguyen et al., (2017) is adopted centering on perceived behaviours and attitudes in leaders and display of values and ethics and motivation of employees. For transactional leadership style the scale by Deichmann and Stam (2015) is adopted based on a five-item scale focused on feedback and control.

\subsection{Data Collection}

This study adopts a self-administered survey method to collect the data to maximise response rates and convenience for participants (Saunders et al., 2009; Kvale, 2008). Access was agreed with key personnel working at the sampled organisations along with consent to disseminate the online questionnaire. Communications to participants included a link to the survey sited on SurveyMonkey, a widely utilised secure online survey tool by professional and academic researchers. Opportunities were provided to participants to read information on the study and also confirm consent after which they could complete the survey. The demographic profile of participants in the survey shows that a majority $68 \%$ possessed a university degree while $30 \%$ were educated to post graduate level. Of the participants $61 \%$ had tenure of 11 years, while just under a third had tenure of 6-11 years and 7\% possessed tenure of 1-5 years. Over half (53\%) reside in Abu Dhabi while $22 \%$ of the sample are evenly divided between Sharjah and Fujiwara. The sample mainly consisted of employees (39\%) in addition to heads of section (30\%) and officer/technical positions (21\%) while senior managers comprised $5 \%$. Participants are drawn from across a number of departments with $39 \%$ working in civil defence, $25 \%$ in immigration, $26 \%$ in police operations and $10 \%$ in human resources.

\section{Results}

Inferential analysis was conducted using structural equation modelling (SEM) adopting a path least squares approach. SEM is widely employed for applied multivariate statistical analyses utilised in the social sciences (Anderson and Gerbing, 1988; Hair et al., 2017).

\subsection{Evaluation of Measurement Model}

Evaluation of the measurement model was conducted for internal consistency, convergent validity and discriminant validity. Assessment of the measurement model is based on criteria for indicator reliability based on outer loadings, composite reliability and Cronbach's alpha. For indicator reliability all outer factor loadings exceeded 0.70 threshold for Cronbach's alpha (Hair et al., 2017; Nunnally, 1978). Internal consistency is further established with acceptable scores for composite reliability (Table 1) of all variables between 0.70 and 0.90 . For convergent validity the applied criteria specifies Average Variance Extracted (AVE) to be $>0.50$ (Hair et al., 2017) where in all cases AVE ranged between 0.53 and 0.74 (Table 1). Discriminant validity was confirmed assessing the degree to which constructs are distinct from each other based on the criterion that the outer loading for an indicator in relation to the respective construct did not exceed any of its cross-loadings (Hair et al., 2017). Applying the Fornell-Larcker criterion (Fornell \& Larcker, 1981) AVE scores were higher than the squared correlations with all other factors in the model. Furthermore, applying the Heterotrait-Mono-trait (HTMT) criterion, ratios were within the acceptable range confirming discriminant validity on this criterion; all ratios recorded statistically significant t-statistics between 2.79 and 33.76 ( $p<0.001)$ (Henseler et al., 2015). 
Table 1. Composite Reliability and AVE

\begin{tabular}{lccccccccccrrr}
\hline & BU & IO & TD & PD & CL & MA & UA & TA & TF & HI & RA & TE & EN \\
\hline CR & .89 & .91 & .92 & .88 & .82 & .73 & .72 & .88 & .80 & .89 & .84 & .82 & .91 \\
AVE & .62 & .70 & .67 & .74 & .69 & .59 & .58 & .53 & .52 & .69 & .68 & .70 & .69 \\
\hline
\end{tabular}

Note. BU(Bottom Up) IO(Inside-Out) TD(Top Down) PD(Power Distance) CL(Collectivism) MA(Masculinity) UA(Uncertainty Avoidance)

TA(Transactional Leadership) TF(Transformational Leadership) HI(Hierarchical) RA(Rational) TE(Team) EN(Entrepreneurial).

\subsection{Model fit}

In PLS path modelling, the main measure for assessing the model for fit is the standardised root mean square residual (SRMR) (Hu and Bentley, 1999). Recent evidence based on simulations has shown that for model correct specifications SRMR values of 0.06 can be obtained (Henseler et al., 2014). Both in the structural model and the measurement model the SRMR values were significantly below 1 indicating good model fit as indicated in Table 2.

Table 2. Model Fit (SRMR)

\begin{tabular}{llll}
\hline Evaluation & SRMR & T Statistic & P Value \\
\hline Measurement Model & 0.037 & 26.16 & 0 \\
Structural & 0.043 & 30.02 & 0 \\
\hline
\end{tabular}

\subsection{Path Analysis}

The PLS-SEM algorithm was run in Smartpls to obtain path coefficients to assess structural model relationships. The structural model is presented in Figure 2 with the path coefficients displayed along the key paths. Coefficients fall within the range -1 to +1 indicating the negative/positive strength of the relationship between the hypothesised constructs in the model (Hair et al., 2017). Initial inspection of Figure 2 shows potentially significant relationships between both the two leadership styles on the three innovation strategies and national culture dimension of uncertainty avoidance and innovation strategies.

To assess the statistical significance of these paths the bootstrapping routine was applied to obtain $t$ statistics and the associated $p$ values for all paths. In terms of the structural relationships the results presented in Figure 2 point to a number of statistically significant path coefficients. In terms of leadership style 错误!未找到引用源。 shows that transactional leadership had negative effect on bottom up innovation $(\beta-0.315)$ and negative effect on in-out strategy ( $\beta-0.354)$ but a positive relationship with top down $(\beta$ 0.495). In contrast transformational leadership had positive relationship with bottom up innovation ( $\beta$ 0.331) and in-out innovation ( $\beta 0.05)$.

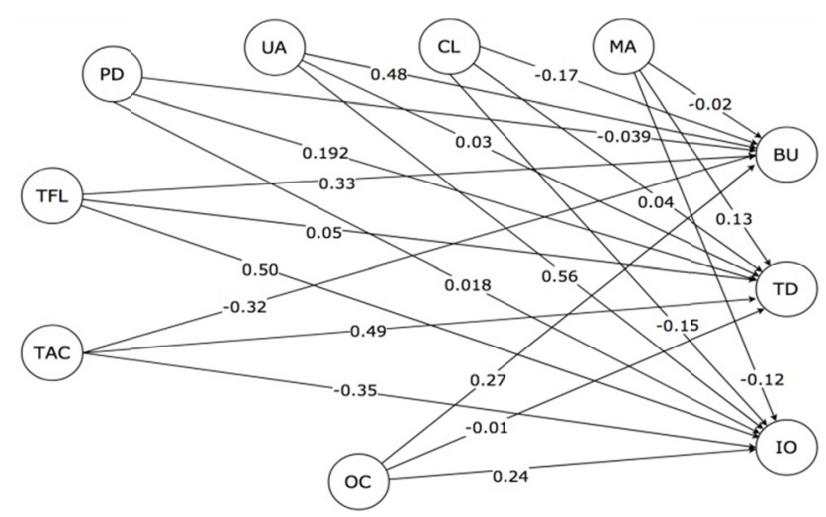

Figure 2. Structural model results

Of the four national culture variables collectivism had a small negative effect on bottom up innovation ( $\beta-0.173$ ) and in-out innovation $(\beta-0.15)$. Masculinity had negative effect on bottom up $(\beta-0.019)$ but a positive effect on top-down innovation $(\beta$ 0.128). Power distance had positive effect on top-down innovation ( $\beta$ 0.195). 
Uncertainty avoidance had a positive relationship with the three innovation strategies: bottom-up innovation ( $\beta$ 0.48 ), in-out innovation ( $\beta$ 0.555) and top-down innovation ( $\beta 0.031)$.

Organisational culture had a positive effect on bottom up innovation $\left(\begin{array}{l}\beta \\ 0.265)\end{array}\right)$ and positive effect on in-out innovation ( $\beta$ 0.241). In regards to the impact of organisational culture on innovation strategies the findings showed there were varied effects from different types of organisational cultures. Hierarchical culture had a negative effect on bottom up innovation ( $\beta-0.454)$ and a strong negative impact on in-out innovation ( $\beta-0.653)$ but a small positive impact on top down innovation ( $\beta$ 0.031). Rational culture exhibited a negative association on all three innovation strategies: bottom up innovation $(\beta-0.004)$, in-out innovation $(\beta-0.095)$ and top down innovation ( $\beta$-0.031). Team culture had moderate positive effects on bottom up innovation ( $\beta$ 0.184), in-out innovation $(\beta$ 0.199) and top down innovation $(\beta$ 0.036). Entrepreneurial culture was found to have a strong positive effect on both bottom up innovation $(\beta 0.235)$ and especially in out innovation ( $\beta$ 0.542) while having a negative effect on top down innovation ( $\beta-0.041)$.

National culture dimensions and organisational culture were tested to establish whether national or organisational culture moderated the relationship between leadership styles and innovation strategies. Power distance, collectivism and uncertainty avoidance exhibited a negative moderating effect on the relationship on transformational leadership and bottom-up innovation (Power distance exhibited medium negative effect, -0.22 , uncertainty avoidance -0.097 , and collectivism -0.115). Power distance had a small negative effect on the relation between transformational leadership and in-out strategy. In the case of transactional leadership and innovation strategies, uncertainty avoidance exhibited a negative moderating effect (-0.097). All other moderator and path combinations tested showed no significant effects. Overall the results indicated that national culture dimensions exhibit a small-medium moderating effect on the relationship between transformational leadership and open innovation strategies (bottom-up and in-out innovation strategies).

Organisational culture types were also tested for moderation effect on the relationship between the two leadership styles and the three innovation strategies. There were mixed results for the moderation effect of each type of culture. Of the 24 paths examined for moderation only 13 revealed a moderating effect that were statistically significant. Notably, in all cases the effect was small. Hierarchical culture negatively moderated the relationship between transformational leadership and bottom-up innovation (-0.097) and in-out innovation $(-0.081)$; and the relationship between transactional leadership and top-down innovation $(-0.051)$. Rational culture moderated the relationship between transformational leadership and bottom-up innovation (-0.074) and in-out innovation (-0.138) but no other moderating effects for other paths. Team culture exerted a moderating effect on the relationship between transformational leadership and bottom-up innovation (0.106) and in-out innovation (0.119); and positive moderating effect on the relationship between transactional leadership style and bottom-up innovation (-0.102) and in-out innovation (-0.165). Finally, entrepreneurial culture exhibited small moderating effect on the relationship between transformational leadership and bottom-up innovation (0.073) and in-out innovation (0.040); and small negative moderating effect for the relationship between transactional leadership style and bottom-up innovation (-0.065) and in-out innovation (-0.054).

\subsection{Assessment of Predictive Relevance}

These results were subject also to assessment of the predictive power R2, effect sizes (f2) and predictive relevance (Q2) of the relationships in the structural model. Effect size $\mathrm{f} 2$ results showed that the nine paths were statistically significant. The coefficient of determination (R2) is the most widely used measure for the structural model and reflects the predictive power of the model (Hair et al., 2017). The R2 assessment confirmed the structural model's predictive power (Hair et al., 2017) with moderate effects for the endogenous variables in Table 3.

Table 3. Assessment of Predictive Relevance

\begin{tabular}{llll}
\hline Evaluation & $\mathrm{R}^{2}$ & T Statistic & P Value \\
\hline Bottom Up Strategy (BUS) & 0.353 & 9.51 & 0 \\
In-Out Strategy (IOS) & 0.459 & 12.25 & 0 \\
Top Down Strategy (TDS) & 0.604 & 20.45 & 0 \\
\hline
\end{tabular}

$\mathrm{Q}^{2}$ measures the predictive relevance of a model and values greater than zero for particular endogenous variables under examination. Table 4 shows the sum of squared observations (SSO), the sum of the square predictions errors (SSE) and $\mathrm{Q}^{2}$ values. $\mathrm{Q}^{2}$ values for the three endogenous constructs were significantly above zero 
providing support for predictive relevance of the structural model.

Table 4. $\mathrm{Q}^{2}$ Predictive Relevance of a Model

\begin{tabular}{llll}
\hline Endogenous Variables & SS0 & SSE & $\mathrm{Q}^{2}(=1-\mathrm{SSE} / \mathrm{SSO})$ \\
\hline Bottom Up Strategy (BUS) & $2,268.00$ & $1,890.40$ & 0.166 \\
In-Out Strategy (IOS) & $2,268.00$ & $1,714.95$ & 0.244 \\
Top Down Strategy (TDS) & $3,024.00$ & $1,931.14$ & 0.361 \\
\hline
\end{tabular}

\subsection{Hypothesis Testing}

The data analysis was applied to test the six central hypotheses proposed in this research. Hypothesis 1 proposes that transformational leadership style is positively related to innovation strategies, specifically:

Hla. Transformational leadership style has a positive effect on bottom-up innovation

H1b. Transformational leadership style has a positive effect on top-down innovation

H1c. Transformational leadership style has a positive effect on in-out innovation

The results provide support for $\mathrm{H} 1 \mathrm{a}$ and $\mathrm{H} 1 \mathrm{c}$, however the proposed positive effect of transformational leadership on top-down innovation (H1b) is rejected. Hypothesis 2 proposes that transactional leadership style is positively related to innovation strategies, specifically:

H2a. Transactional leadership style has a positive effect on bottom-up innovation.

H2b. Transactional leadership style has a positive effect on top-down innovation.

H2c. Transactional leadership style has a positive effect on in-out innovation.

The positive effect of transactional leadership on top-down innovation is supported $(\mathrm{H} 2 \mathrm{~b})$, however there was a negative effect on bottom-up and in-out innovation therefore hypotheses $\mathrm{H} 2 \mathrm{a}$ and $\mathrm{H} 2 \mathrm{c}$ are rejected. Hypotheses 3 and 4 address cultural dimensions. H3 proposes that national culture dimensions are positively related to innovation strategies. This is addressed specifically for each national culture dimension:

H3a. Power distance has a positive effect on innovation strategies.

H3b. Uncertainty avoidance has a positive effect on innovation strategies.

H3c. Collectivism has a positive effect on innovation strategies.

H3d. Masculinity has a positive effect on innovation strategies.

The results indicate partial acceptance for this hypothesis as some national culture dimensions indicate a positive relationship. Power distance $(\mathrm{H} 3 \mathrm{a})$ had a positive effect on top-down innovation while uncertainty avoidance (H3b) had a positive effect on both bottom-up and in-out innovation. However collectivism (H3c) demonstrated a negative effect on bottom up and in-out innovation. Masculinity (H3d) had a positive relationship with top down innovation but a negative relationship with in-out innovation. Hypothesis 4 proposes that organisational culture orientation is positively related to innovation strategies, specifically:

H4a. Hierarchical culture type has a positive effect on innovation strategies.

H4b. Rational culture type has a positive effect on innovation strategies.

H4c. Team culture type has a positive effect on innovation strategies.

H4d. Entrepreneurial culture type has a positive effect on innovation strategies.

The positive effect of organisational culture orientation on innovation strategies is partially supported by the results. Hierarchical culture type (H4a) indicated a negative effect on bottom-up and in-out innovation while Rational culture (H4b) had a negative relationship with in-out innovation. However team culture (H4c) and entrepreneurial culture types (H4d) had a positive effect on both bottom-up and in-out innovation. Hypothesis 5 proposes that national culture moderates the relationship between leadership style and innovation strategies, specifically:

H5a. Power distance moderates the relationship between leadership style and innovation strategies.

H5b. Uncertainty avoidance moderates the relationship between leadership style and innovation strategies.

H5c. Collectivism moderates the relationship between leadership style and innovation strategies. 


\section{H5d. Masculinity moderates the relationship between leadership style and innovation strategies.}

There is some support for this hypothesis as specific national culture dimensions either positively or negatively moderated the relationship between leadership style and innovation strategies while others demonstrated no effect. Power distance (H5a) negatively moderated the relationship, while uncertainty avoidance (H5b) and collectivism $(\mathrm{H} 5 \mathrm{c})$ exhibited a negative moderating effect on the relationship between transformational leadership and bottom-up innovation while power distance had a negative moderating effect on in-out innovation. In the case of transactional leadership and innovation strategies, uncertainty avoidance exhibited a negative moderating effect on bottom-up innovation. Hypothesis 6 proposes that organisational culture orientation moderates the relationship between leadership style and innovation strategies, specifically:

H6a. Hierarchical culture type moderates the relationship between leadership style and innovation strategies.

H6b. Rational culture type moderates the relationship between leadership style and innovation strategies.

H6c. Team culture type moderates the relationship between leadership style and innovation strategies.

H6d. Entrepreneurial moderates the relationship between leadership style and innovation strategies.

The results show that this hypothesis can be partially accepted. Hierarchical culture (H6a) negatively moderated the relationship between transformational leadership and bottom-up innovation and in-out innovation and the relationship between transactional leadership and top-down innovation. Rational culture (H6b) moderated the relationship between transformational leadership and bottom-up innovation and in-out innovation. Team culture (H6c) exerted a positive moderating effect on the relationship between transformational leadership and bottom-up innovation and in-out innovation; and positive moderating effect on the relationship between transactional leadership style and bottom-up innovation and in-out innovation. Finally, entrepreneurial culture (H6d) exhibited a positive moderating effect on the relationship between transformational leadership and bottom-up innovation and in-out innovation and negative moderating effect for the relationship between transactional leadership style and bottom-up innovation and in-out innovation.

\section{Discussion}

\subsection{Leadership Styles}

The findings showed that transformational leadership exerted a strong positive influence on open (bottom-up and in-out) innovation strategies, while transactional leadership positively affected top-down innovation. The effect of transformational leadership on open innovation aligns with the strong relationship identified in prior research (Yadav; 2013; Mejia-Trejo et al. 2013). Transformational leadership implies recognition of the need to innovate and change. The high degree of uncertainty in the UAE policing environment could be driving greater bottom-up engagement and help explain this result. Uncertainty can increase the receptivity of senior leadership to new ideas and solutions that underpin new understanding of the external environment (Hansen, 2015). Thus middle managers may be promoting knowledge sharing, team work and collaboration to address the key issues they face across the police sector.

The positive association identified between transactional leadership and top down innovation is consistent with the literature which emphasises multiple ways innovation performance is impacted (Jansen et al., 2009). In particular transactional leadership promotes exploitative innovation through learning flows fed forward by means of active management by exception and contingent reward behaviours, providing the focus and control required to drive efficiency and make incremental improvements in active routines and practices (Jansen et al., 2009). The finding could be explained in the role of middle managers that is less transformational and more transactional as subordinates in their dealings with senior management. Government and senior civil servants are the key actors forming the strategic responses and new priorities and vision which drive top down innovation (Borins, 2002). This aligns with the emergent leadership culture in the UAE and points to the impact of the external context and top leadership vision in creating a strong innovation agenda (Buhumaid et al., 2016; Al-Darmaki, 2015).

Based on this study's findings, transformational leadership may be associated with innovation driven by exploratory knowledge, while transactional leadership may be focused on implementation of top-down innovation to exploit existing knowledge and drive efficiency. This duality may explain the different relationships with innovation strategies.

\subsection{National Culture}

The findings revealed that different national culture dimensions positively and negatively related to innovation strategy. A key result was the strong association between uncertainty avoidance (UA) and open innovation 
strategies, an unexpected result given the consensus in the literature that a cultural tendency towards UA leads to lower levels of innovation (Beyene et al., 2016; Bockstedt et al. 2015; Shane, 1995, 1993). A new dynamic between the need for control and the need to align with the external environment is thus suggested, possibly impacted by the external challenging and complex business context that significantly impacts police organisations, generating significant pressures on managers in which they may have no option but to share risk and engage in shared decision-making, communication, delegation and collaboration. This is a logical assumption given that risk reduction is a key characteristic of UA cultures (Hofstede, 2001), and presents a more nuanced picture of the relationship between UA and innovation than suggested in prior literature.

Power distance (PDI) had a strong positive effect on top down innovation, not an unexpected result given that top-down innovation places strong emphasis on the role of senior leadership (Currie et al., 2008). The result aligns with the risk averse and hierarchical culture that characterises the UAE and suggests that national culture influences a top-down focus and tight control on innovation strategy. Top down innovation methods dominate in the public sector (Albury, 2005; Mulgan and Albury, 2003) However, as this result is balanced with a strong relationship between transformational leadership and open innovation, a balanced or an incremental strategy is implied. Further research is needed to understand this dynamic as it may be possible that at lower organisational levels there is emphasis on participation and engagement and support for accessing external sources of knowledge, while at higher levels of management national culture exerts a higher degree of influence and adheres to form in terms of top-down strategy development.

The negative relationship identified between collectivism and bottom-up innovation points to an inhibiting effect, consistent with the overall position in the literature that collectivist traits are less conducive to innovation relative to individualistic cultures (Waarts and Van Everdingen, 2005; Herbig and Dunphy, 1998). Research indicates that a collectivist culture can restrict information circulation and motivate senior management to place more trust in their informed subordinates (Al-Adaileh and Al-Atawi, 2011; Sabri, 2005). This implies a degree of secrecy and the potential for withholding knowledge from those outside of personal networks. In such cultures subordinates may need to be explicitly empowered as they are reluctant to engage with those in senior positions, potentially inhibiting spontaneous bottom-up initiatives.

Masculinity (MAS) was positively associated with top down innovation, partially explained by an orientation in masculine societies towards performance, status and achievement based on rewards (Efrat, 2014; Shane, 1993). The lack of relationship with bottom-up innovation and the negative influence on in-out innovation lends some support to the literature which suggests masculinity negatively affects innovation (Kaasa et al., 2013). It may well be that high masculinity cultures due to their competitiveness devote less time to developing internal relationships and the social capital which enable them to identify and utilise the innovation capabilities of employees, and be less likely to reciprocate and build trust.

\subsection{Organisational Culture}

Different organisational cultures had differentiated effects on particular innovation strategies and the findings provided evidence that more flexible and open cultures had a stronger association with bottom-up innovation. This supports literature indicating that different types of organisational cultures can facilitate or impede innovation (Naranja-Valencia, 2015; Cameron and Quinn, 2006). In terms of culture types, results pointed to a strong and positive effect of the entrepreneurial culture on bottom-up innovation, consistent with prior research emphasising that the characteristic external focus and flexibility of entrepreneurial cultures (Helfrich et al., 2007) can promote an orientation towards innovation (Skerlavaj et al., 2010; Droge et al., 2008). A team culture had a moderate positive relationship with bottom-up innovation, supporting evidence that the decentralisation characteristic of team cultures encourages bottom-up activities and plans (Kim et al., 2014). Hierarchical organisations had a reduced relationship with bottom-up strategies, underlining that the emphasis on formal structures, order and stability and rules and procedures may have a negative effect on organisational innovation (Naranjo-Valencia et al., 2011). Bottom-up initiatives mainly occur in environments in which varied ideas are shared and valued and employee experimentation with novel ideas is facilitated (Kim et al., 2014). These factors may partly explain the positive relationship between organisational culture and bottom-up innovation identified in this research. Middle managers may have increased latitude to promote and encourage sharing of knowledge, reflected in the major UAE cultural shift towards promoting the value of knowledge and organisational learning.

Findings revealed a small but positive effect of organisational culture on in-out innovation, suggesting that organisational culture is facilitating the engagement of internal and external organisational stakeholders to access knowledge, capabilities and resources (Lee et al., 2016). However these effects were different for different organisational cultures. Hierarchical cultures exhibited a strong negative impact, while entrepreneurial culture 
had a significant positive association aligning with the leveraging of ideas and innovation to the external environment to increase organisational value which is a key component of this approach (Osterwalder \& Pigneur, 2010; Gassman \& Enkel, 2004).

\subsection{Moderating Effect of National and Organisational Culture}

The findings on national culture indicated that some culture dimensions exerted a small to medium moderating effect on the relationship between leadership style and innovation strategies. In testing the moderating effect of national culture dimensions, of the eight relationships only power distance, uncertainty avoidance and collectivism had a moderating effect on the relationship between leadership style and open innovation strategies (bottom-up and inside-out). Power distance exhibited medium negative effect while the effect for uncertainty avoidance and collectivism was small. Therefore overall national culture did not exhibit a strong moderating effect. The literature has questioned the extent to which national culture exerts a greater influence than organisation culture and the emphasis on national culture over organisational culture (Kotter \& Heskett, 1992; Barney, 1991; O'Reilly et al., 1991). The lack of strong moderating effect in these findings suggests that strategies may not be as bound to culture as originally assumed by scholars, and organisations have greater flexibility in exploring strategies that are more aligned with external conditions or organisational context. There may be more willingness at top level to distribute power than is traditionally assumed, albeit under certain conditions, and greater latitude for power sharing between different levels of management and potentially creative decision-making structures. This may mean that a greater autonomy is enabled in high power distance contexts than Hofstede's assumptions would suggest. In terms of collectivism, this may be explained by the influence of social media that could well be promoting individual-based social networking. The technological and social development in terms of social media represents a major driver of organisational change. Social media is considered to be a diverse and multi-faceted technology reflecting a broad capacity for participatory and interactive communication within social contexts that create organisations. It is evident that a young management workforce are networked and highly connected via this media across organisational boundaries. Social networking adoption by UAE citizens has grown sharply, with a social media penetration rate of $60 \%$ (Salem \& Mourtada, 2015). Organisations are increasingly adopting and utilising social media and social software systems to facilitate collaborative problem solving especially among geographically dispersed employees (Sutanto et al., 2011). In the UAE, the significance of social media to engage citizens on the issue of transforming the education and healthcare sectors is underscored by the government's national brainstorming initiative (Salem, 2014).

In addition, there may well be individual and group level differences that mitigate the impact on national culture. One explanation and an area for further investigation is the cultural diversity in the UAE. External and organisational pressures may exert influence that transcends national cultural boundaries. This is consistent with the notion of cultural adaptability that emphases the formation of new culture (Nilsson and Anderson 2004; Selmer \& de Leon, 2002). In light of globalisation and the immense cultural diversity of the UAE and exposure of its leaders to cross-cultural practices the findings may point to evolving cultural values.

Uncertainty avoidance was expected to significantly moderate the relationship between leadership styles and open innovation strategies. However, the small moderating effect of uncertainty avoidance on the relationship between transformational leadership and bottom-up suggests that this dimension is not significantly binding. The moderating effect of uncertainty avoidance was also weak on the relationship between transactional leadership and innovation strategies, exhibiting a negative moderating effect. Thus uncertainty avoidance did not significantly constrain or enable the two different leadership styles. This contrasts with previous research which lends support for national culture as a moderator of the relationship between entrepreneurial orientation and business performance (Petrovic, et al., 2015; Frank et al., 2010; Rauch et al., 2009).

Power distance exhibited a medium negative effect on the relationship between transformational leadership and bottom-up innovation. The moderating effect of national culture might suggest control remains centralised with senior managers. This is consistent with the strong positive relationship between transactional leadership and top-down innovation. However, power distance did not moderate the relationship in terms of other paths, notably between transformational leadership and inside-out leadership. This lack of national culture constraint might explain the positive relationship between transformational leadership and open innovation strategies where managers possess greater autonomy. One explanation could be that more control is passed to middle managers from seniors to exploit internal knowledge and ensure that it is diffused and shared among external agencies and units. Continuous change is now endemic in the UAE public sector, emphasising a critical role for middle managers to drive change. Divergent behaviour arising from middle manager championing and enabling initiatives operationally has been acknowledged in the literature (Burgelman, 1983; Kanter, 1983). Multiple 
scholars have emphasised that self-organisation is the core concept emerging from complexity theory (Arena, 2009; Olson \& Eoyang, 2001; Lichtenstein, 2000; Zimmerman et al., 1998). Self-organisation is held to represent a dynamic process in which individuals mutually and continually adapt their behaviours to better manage change in response to internal and external environmental demands (Lindberg et al., 2008).

The results for organisational culture found that the four types of organisational culture (hierarchical, rational, team, entrepreneurial) only marginally moderated the effect between leadership styles and innovation strategies. Similarly to national culture, overall the results do not provide conclusive evidence for organisational culture types as moderators. Twenty paths for the four culture types were tested for moderation effect against each of the three innovation strategies. For all culture types the moderating effect was predominantly small. As expected hierarchical culture had small negative effect on the relationship between leadership style and innovation strategy. In contrast, team culture and more flexible and open culture types had small positive moderating effect on open innovation strategies.

Therefore while organisation culture types do moderate the relationship between leadership style and innovation strategy the effects were small or extremely marginal and therefore not conclusive. This finding may suggest that culture types are not as constraining as perceived. Possibility irrespective of the cultural context other factors may be enabling middle managers to exercise greater degrees of autonomy and freedom in terms of open innovation behaviours.

\section{Conclusion}

This study explored the relationships between leadership styles and innovation strategies and the effect of national and organisational culture. The findings reveal that leadership styles have distinct relationships with innovation strategies, and point to a duality in terms of transformational and transactional leadership and innovation. It appears that middle managers apply their styles differently depending on the context and represent a bridge or divide between the two levels of the organisation to provide flexibility while at the same time retaining control for upper management in line with cultural values. This research contributes theoretical insights on the role of leadership style and culture and their effect on innovation in public sector organisations within the Arab context. In particular the research verifies the relative effect of national culture dimensions on organisational culture, organisational innovativeness and the role of leadership styles in this context. The findings of this study expand knowledge on innovation in Arab cultures and the interaction of leadership style and national culture dimensions and the extent to which leadership mediates innovation. The relationship between national culture dimensions provide support for the notion of a balanced approached to innovation management. National culture does not appear to be an entirely restraining factor in innovation. A key finding was the strong positive association between UA and open innovation strategies, emphasising a new dynamic or dilemma between the need for control and the need to align with the external environment and the myriad changes faced by police organisations. The findings suggest that the external context influences national culture and point to different impacts on innovation orientation depending on conditions. In terms of organisational culture the relationship with innovation strategy varied depending on the culture, with more flexible open structures influencing higher levels of open innovation. Notably the findings indicated that national culture and organisational culture were not strong moderators for innovative strategies. In other words, innovation strategies may not be entirely bound by culture suggesting a more complex dynamic. This study also makes a positive theoretical contribution to innovation theory in the integration of top down and bottom up perspectives in the generation of innovation. Understanding of both approaches has been enlarged by this study through the identification of culture as a contingency factor that influences the dynamic between top-down planning and bottom up learning. A key limitation should be acknowledged in relation to this research which is based solely on a quantitative approach to examine the complex relationships between leadership, culture and innovation strategies. This topic would benefit from qualitative research findings to delve into the interactions effect of the constituent elements of transformational leadership and socialisation perspectives for interaction effects between the key dimensions.

\section{References}

Al Maktoum, M. (2015). The Sheikh Khalifa Government Excellence Program. Retrieved from https://www.skgep.gov.ae/en/media-center/press-news/4G

Al-Adaileh, R. M., \& Al-Atawi, M. S. (2011). Organizational culture impact on knowledge exchange: Saudi Telecom context. Journal of Knowledge Management, 15(2), 212-230. http://dx.doi.org/10.1108/13673271111119664 
Al-Darmaki, O. (2015). Managing change: An investigation into readiness for change within the public sector in the UAE: The case of the Ministry of Interior (MOI). Doctoral dissertation, Liverpool John Moores University.

Anderson, J. C., \& Gerbing, D. W. (1988). Structural equation modeling in practice: A review and recommended two-step approach. Psychological Bulletin, 103(3), 411-423.

Andries, P., \& Czarnitzki, D. (2014). Small firm innovation performance and employee involvement. Small Business Economics, 43(1), 21-38. https://doi.org/10.1007/s11187-014-9577-1

Avolio, B. J., \& Bass, B. M. (2002). Manual for the Multifactor Leadership Questionnaire (Form 5x). Redwood City, CA: Mindgarden.

Avolio, B. J., Bass, B. M., \& Jung, D. I. (1999). Re-examining the components of transformational and transactional leadership using the Multifactor Leadership. Journal of Occupational and Organizational Psychology, 72(4), 441-462. https://doi.org/10.1348/096317999166789

Ayoun, B. M., \& Moreo, P. J. (2008). The influence of the cultural dimension of uncertainty avoidance on business strategy development: A cross-national study of hotel managers. International Journal of Hospitality Management, 27(1), 65-75. https://doi.org/10.1016/j.ijhm.2007.07.008

Bagozzi, R. Y. B., \& Baumgartner, P. J. (1994). The evaluation of structural equation models and hypothesis testing. Principles of Marketing Research. Blackwell, Cambridge, MA, USA.

Baker, K. A. (2002). Organizational culture. $\quad$ Retrieved from http://www.au.af.mil/au/awc/awcgate/doe/benchmark/ch11.pdf

Baptista, J., Wilson, A. D., Galliers, R. D., \& Bynghall, S. (2017). Social media and the emergence of reflexiveness as a new capability for open strategy. Long Range Planning, 50(3), 322-336. https://doi.org/10.1016/j.lrp.2016.07.005

Bass, B. M., \& Riggio, R. E. (2006). Transformational leadership. New York: Psychology Press.

Beck, B. E., \& Moore, L. F. (1985). Linking the host culture to organizational variables. In P. J. Frost et al., Organizational culture. Newbury Park, Calif.: Sage Publisher.

Berman, E. M., \& Kim, C. G. (2010). Creativity management in public organizations: Jump starting innovation. Public Performance \& Management Review, 619-652. http://dx.doi.org/10.2753/PMR1530-9576330405

Bertot, J. C., Jaeger, P. T., \& Grimes, J. M. (2010). Using Icts to create a culture of transparency: E-Government and social media as openness and anti-corruption tools for societies. Government Information Quarterly, 27(3), 264-271. http://dx.doi.org/10.1016/j.giq.2010.03.001

Beyene, K. T., Sheng, S. C., \& Wei, W. W. (2016). Linking national culture and product innovation performance: What really influences the interplay, strategy formulation or implementation effectiveness? International Journal of Business and Management, 11(2), 184-196. http://dx.doi.org/10.5539/ijbm.v11n2p184

Biygautane, M., \& Al-Yahya, K. (2011). Knowledge management in the UAE's public sector: The case of Dubai. In Dubai School of Government, Paper Presented at the Gulf Research Meeting Conference at the University of Cambridge, UK.

Bockstedt, J., Druehl, C., \& Mishra, A. (2015). Problem-solving effort and success in innovation contests: The role of national wealth and national culture. Journal of Operations Management, 36(May), 187-200. https://doi.org/10.1016/j.jom.2014.12.002

Bono, J. E., \& Anderson, M. H. (2005). The advice and influence networks of transformational leaders. Journal of Applied Psychology, 90(6), 1306-1314. http://dx.doi.org/10.1037/0021-9010.90.6.1306

Borins, S. (2002). Leadership and innovation in the public sector. Leadership \& Organization Development Journal, 23(8), 467-76. https://doi.org/10.1108/01437730210449357

Bruhn, M., \& Ahlers, G. M. (2017). Integrated communication in the innovation process: An approach to integrated innovation communication. Strategy and Communication for Innovation, 205-225.

Buhumaid, H., Constantin, M., \& Schubert, J. (2016). How the UAE government modernized citizen services. McKinsey\&Company.

Burns, J. M. (1978). Leadership. New York: Harper \& Row. 
Caillier, J. G. (2015). Transformational leadership and whistle-blowing attitudes: Is this relationship mediated by organizational commitment and public service motivation? The American Review of Public Administration, 45(4), 458-475. https://doi.org/10.1177/0275074013515299

Cameron, K. S., \& Quinn, R. E. (2011). Diagnosing and changing organizational culture: Based on the competing values framework. London: John Wiley \& Sons.

Carmeli, A. (2005). The relationship between organizational culture and withdrawal intentions and behaviour. International Journal of Manpower, 26(2), 177-195. https://doi.org/10.1108/01437720510597667

Cortimiglia, M. N., Ghezzi, A., \& Frank, A. G. (2016). Business model innovation and strategy making nexus: Evidence from a cross-industry mixed-methods study. R\&D Management, 46(3), 414-432. https://doi.org/10.1111/radm.12113

Currie, G., Humphreys, M., Ucbasaran, D., \& McManus, S. (2008). Entrepreneurial leadership in the English public sector: Paradox or possibility? Public Administration, 86(4), 987-1008. https://doi.org/10.1111/j.1467-9299.2008.00736.x

Deichmann, D., \& Stam, D. (2015). Leveraging transformational and transactional leadership to cultivate the generation of organization-focused ideas. The Leadership Quarterly, 26(2), 204-219. https://doi.org/10.1016/j.leaqua.2014.10.004

Deschamps, J. P. (2005). Different leadership skills for different innovation strategies. Strategy \& Leadership, 33(5), 31-38. https://doi.org/10.1108/10878570510616861.

Droge, C., Calantone, R. J., \& Harmancioglu, N. (2008). New product success: Is it really controllable by managers in highly turbulent environments? Journal of Product Innovation Management, 25(3), 272-286. https://doi.org/10.1111/j.1540-5885.2008.00300.x

Dvir, T., Eden, D., Avolio, B. J., \& Shamir, B. (2002). Impact of transformational leadership on follower development and performance: A field experiment. Academy of Management Journal, 45(4), 735-744. https://doi.org/10.5465/3069307

Efrat, K. (2014). The direct and indirect impact of culture on innovation. Technovation, 34(1), 12-20. https://doi.org/10.1016/j.technovation.2013.08.003

Engelen, A., Schmidt, S., Strenger, L., \& Brettel, M. (2014). Top management's transformational leader behaviors and innovation orientation: A cross-cultural perspective in eight countries. Journal of International Management, 20(2), 124-136. https://doi.org/10.1016/j.intman.2013.04.003

Fornell, C., \& Larcker, D. F. (1981). Evaluating structural equation models with unobservable variables and measurement error. Journal of Marketing Research, 18(1), 39-50.

Gassmann, O., \& Enkel, E. (2004). Towards a theory of open innovation: three core process archetypes. Proceedings of the R\&D Management Conference, Lisbon, Portugal, July 6-9.

Goodwin, G. C., Graebe, S. F., \& Salgado, M. E. (2001). Control system design. Prentice Hall.

Goyal, S., Kaur, P., \& Singh, K. (2015). Role of HR and financial services in making "Make in India" campaign a success. IOSR Journal of Business and Management, 17(2), 20-24.

Gumusluoğlu, L., \& Ilsev, A. (2009). Transformational leadership and organizational innovation: The roles of internal and external support for innovation. Journal of Product Innovation Management, 26(3), 264-277. https://doi.org/10.1111/j.1540-5885.2009.00657.x

Hansen, J. R. (2015). A bottom-up perspective on leadership of collaborative innovation in the public sector: The social construction of leadership for disadvantaged city districts in the city of Copenhagen. Doctoral dissertation, Aalborg University, The Faculty of Engineering and Science and Center for Design, Innovation and Sustainable Transitions.

Helfrich, C. D., Weiner, B. J., McKinney, M. M., \& Minasian, L. (2007). Determinants of implementation effectiveness: Adapting a framework for complex innovations. Medical Care Research and Review, 64(3), 279-303. https://doi.org/10.1177/1077558707299887

Helmreich, R. L., \& Merrit, A. C. (1998). Culture at work in aviation and medicine: National, organisational and professional influences. Farnham, UK: Ashgate Publishing.

Henseler, J., Dijkstra, T. K., Sarstedt, M., Ringle, C. M., Diamantopoulos, A., Straub, D. W., Ketchen, D. J. Jr, Hair, J. F., Hult, G. T. M., \& Calantone, R. J. (2014). Common beliefs and reality about PLS: Comments on 
Rönkkö \& Evermann (2013), Organizational Research Methods, 17(2), 182-209. https://doi.org/10.1177/1094428114526928

Henseler, J., Ringle, C. M., \& Sarstedt, M. (2015). A new criterion for assessing discriminant validity in variance-based structural equation modeling. Journal of the Academy of Marketing Science, 43(1), 115-135. https://doi.org/10.1007/s11747-014-0403-8

Herbig, P., \& Dunphy, S. (1998). Culture and innovation. Cross Cultural Management: An International Journal, 5(4), 13-21. https://doi.org/10.1108/13527609810796844

Hofstede, G. (1980). Culture and organizations. International Studies of Management \& Organization, 10(4), 15-41. https://doi.org/10.1080/00208825.1980.11656300

Hofstede, G. (2001). Culture's consequences: Comparing values, behaviors, institutions, and organizations across nations. Sage Publication, Beverly Hills.

House, R. J., Hanges, P. J., Javidan, M., Dorfman, P. W., \& Gupta, V. (2004). Culture, leadership, and organizations: The Globe study of 62 societies. Sage Publications.

Howell, J. M., \& Higgins, C. A. (1990). Champions of technological innovation. Administrative Science Quarterly, 35, 317-341. https://doi.org/10.2307/2393393

Jansen, J. J., Vera, D., \& Crossan, M. (2009). Strategic leadership for exploration and exploitation: The moderating role of environmental dynamism. The Leadership Quarterly, 20(1), 5-18. https://doi.org/10.1016/j.leaqua.2008.11.008

Kaasa, A., \& Vadi, M. (2010). How does culture contribute to innovation? Evidence from European countries. Economics of Innovation and New Technology, 19(7), 583-604. https://doi.org/10.1080/10438590902987222

Kaasa, A., Vadi, M., \& Varblane, U. (2013). European social survey as a source of new cultural dimensions estimates for regions. International Journal of Cross Cultural Management, 13(2), 137-157. https://doi.org/10.1177/1470595813485379

Katzenbach, J., Steffen, I., \& Kronley, C. (2012). Cultural change that sticks. Harvard Business Review, 90(7), $1-9$.

Kim, S., \& Yoon, G. (2015). An innovation-driven culture in local government: Do senior manager's transformational leadership and the climate for creativity matter? Public Personnel Management, 44(2), 147-168. https://doi.org/10.1177/0091026014568896

Kim, U., Triandis, H. C., Kagitcibasi, C., Choi, S. C., \& Yoon, G. (1994). Individualism and collectivism: Theory, method, and applications. Thousand Oaks, CA: Sage.

Kim, Y. H., Sting, F. J., \& Loch, C. H. (2014). Top-down, bottom-up, or both? Toward an integrative perspective on operations strategy formation. Journal of Operations Management, 32(7), 462-474. https://doi.org/10.1016/j.jom.2014.09.005

Lord, R. G., De Vader, C. L., \& Alliger, G. M. (1986). A meta-analysis of the relation between personality traits and leadership perceptions: An application of validity generalization procedures. American Psychological Association.

Lowe, K. B., Kroeck, K. G., \& Sivasubramaniam, N. (1996). Effectiveness correlates of transformational and transactional leadership: A meta-analytic review of the MLQ literature. The Leadership Quarterly, 7(3), 385-425. https://doi.org/10.1016/S1048-9843(96)90027-2

Martins, E., \& Terblanche, F. (2003). Building organisational culture that stimulates creativity and innovation. European Journal of Innovation Management, 6(1), 64-74. https://doi.org/10.1108/14601060310456337

Mejia-Trejo, J., Sanchez-Gutierrez, J., \& Ortiz-Barrera, M. (2013). Innovation generation and leadership on value creation: The case of software developer sector in Guadalajara, México. Retrieved from https://papers.ssrn.com/sol3/papers.cfm?abstract_id=2390810

Miron, E., Erez, M., \& Naveh, E. (2004). Do personal characteristics and cultural values that promote innovation, quality, and efficiency compete or complement each other? Journal of Organizational Behavior, 25(2), 175-199. https://doi.org/10.1002/job.237

Moynihan, D. P., Pandey, S. K., \& Wright, B. E. (2012). Prosocial values and performance management theory: Linking perceived social impact and performance information use. Governance, 25(3), 463-483. 
https://doi.org/10.1111/j.1468-0491.2012.01583.x

Naranjo-Valencia, J. C., Jiménez-Jiménezb, D., \& Sanz-Valle, R. (2015). Studying the links between organizational culture, innovation, and performance in Spanish companies. RevistaLatinoamericana de Psicología, 48(1), 30-41. https://doi.org/10.1016/j.rlp.2015.09.009

Nazarian, A., Atkinson, P., \& Greaves, L. (2014). The relationship between national culture and organisational culture: case of medium and large size organisations in Iran. Macrotheme Review, 3(6), 66-78.

Newman, K. L., \& Nollen, S. D. (1996). Culture and congruence: The fit between management practices and national culture. Journal of International Business Studies, 27(4), 753-779. https://doi.org/10.1057/palgrave.jibs.8490152

Nguyen, T. T., Mia, L., Winata, L., \& Chong, V. K. (2017). Effect of transformational-leadership style and management control system on managerial performance. Journal of Business Research, 70(January), 202-213. https://doi.org/10.1016/j.jbusres.2016.08.018

Nunnally, J. C. (1978). Psychometric theory. New York: McGraw-Hill.

Osterwalder, A., \& Pigneur, Y. (2010). Business model generation: A handbook for visionaries, game changers, and challengers. John Wiley \& Sons.

Pablo, A. L., Reay, T., Dewald, J. R., \& Casebeer, A. L. (2007). Identifying, enabling and managing dynamic capabilities in the public sector. Journal of Management Studies, 44(5), 687-708. https://doi.org/10.1111/j.1467-6486.2006.00675.x

Reddick, C. G., \& Turner, M. (2012). Channel choice and public service delivery in Canada: Comparing e-government to traditional service delivery. Government Information Quarterly, 29(1), 1-11. https://doi.org/10.1016/j.giq.2011.03.005

Rinne, T., Steel, G. D., \& Fairweather, J. (2012). Hofstede and Shane revisited: The role of power distance and individualism in national-level innovation success. Journal of Cross-Cultural Research, 46, 91-108. https://doi.org/10.1177/1069397111423898

Sabri, H. (2005). Knowledge management in its context: Adapting structure to a knowledge creating culture. International Journal of Commerce and Management, 15(2), 113-128. https://doi.org/10.1108/10569210580000191

Saunders, M., Lewis, P., \& Thornhill, A. (2009). Research methods for business students (5th ed.). Harlow: Pearson Education.

Shamir, B., \& Howell, J. M. (1999). Organizational and contextual influences on the emergence and effectiveness of charismatic leadership. The Leadership Quarterly, 10(2), 257-283. https://doi.org/10.1016/S1048-9843(99)00014-4

Shamir, B., House, R. J., \& Arthur, M. B. (1993). The motivational effects of charismatic leadership: A self-concept based theory. Organization Science, 4, 577-594. https://doi.org/10.1287/orsc.4.4.577

Shane, S. (1993). Cultural influences on national rates of innovation. Journal of Business Venturing, 8(1), 59-73. https://doi.org/10.1016/0883-9026(93)90011-S

Shane, S. A. (1992). Why do some societies invent more than others? Journal of Business Venturing, 7(1), 29-46. https://doi.org/10.1016/0883-9026(92)90033-N

Skerlavaj, M., Song, J. H., \& Lee, Y. (2010). Organizational learning culture, innovative culture and innovations in South Korean firms. Expert Systems with Applications, 37(9), 6390-403. https://doi.org/10.1016/j.eswa.2010.02.080

Skordoulis, R. T. (2012). Change management in higher education: Top-down or bottom-up?. International Journal of Applied Management Education and Development, 1(3), 1-19.

Smale, T. (2016). Why national culture should be at the heart of innovation management. Technology Innovation Management Review, 6(4), 18-25. http://dx.doi.org/10.1287/mnsc.28.12.1421

Spolaore, E. \& Wacziarg, R. (2012). How deep are the roots of economic development? National Bureau of Economic Research Working Paper 18130. Cambridge, MA: National Bureau of Economic Research.

Taylor, M. Z., \& Wilson, S. (2012). Does culture still matter?: The effects of individualism on national innovation rates. Journal of Business Venturing, 27(2), 234-247. https://doi.org/10.1016/j.jbusvent.2010.10.001 
Trompenaars, F., \& Hampden-Turner, C. (1998). Riding the waves of culture. New York: McGaw-Hill.

UAE Gov. (2017). Mohammed Bin Rashid Centre for Government Innovation. Retrieved from https:/uaecabinet.ae/en/details/prime-ministers-initiatives/mohammed-bin-rashid-centre-for-government-in novation

Van Everdingen, Y. M., \& Waarts, E. (2003). The effect of national culture on the adoption of innovations. Marketing Letters, 14(3), 217-232. https://doi.org/10.1023/A:1027452919403

Vera, D., \& Crossan, M. (2004). Strategic leadership and organizational learning. Academy of Management Review, 29(2), 222-240.

Waarts, E., \& Van Everdingen, Y. (2005). The Influence of national culture on the adoption status of innovations: An empirical study of firms across Europe. European Management Journal, 23(6), 601-610. https://doi.org/10.1016/j.emj.2005.10.007

Waldman, D. A., \& Bass, B. M. (1991). Transformational leadership at different phases of the innovation process. The Journal of High Technology Management Research, 2(2), 169-180. https://doi.org/10.1016/1047-8310(91)90002-6

Williams, L. K., \& McGuire, S. J. (2005). Effects of national culture on economic creativity and innovation implementation. The Institutions of Market Exchange.

Wright, B. E., Moynihan, D. P., \& Pandey, S. K. (2012). Pulling the levers: Transformational leadership, public service motivation, and mission valence. Public Administration Review, 72(2), 206-215. https://doi.org/10.1111/j.1540-6210.2011.02496.x

Yadav, L. K. (2013). The commitment conundrum. IUP Journal of Soft Skills, 7(3), 23-30.

Yoo, B., Donthu, N., \& Lenartowicz, T. (2011). Measuring Hofstede's five dimensions of cultural values at the individual level: Development and validation of CVSCALE. Journal of International Consumer Marketing, 23(3-4), 193-210. https://doi.org/10.1080/08961530.2011.578059

\section{Copyrights}

Copyright for this article is retained by the author(s), with first publication rights granted to the journal.

This is an open-access article distributed under the terms and conditions of the Creative Commons Attribution license (http://creativecommons.org/licenses/by/4.0/). 